\title{
El Estilo Cerro del Oro del Horizonte Medio en el valle de Asia
}

\section{The Cerro del Oro style from the Middle Horizon in the Asia Valley}

Rommel Ángeles Falcón ${ }^{\mathrm{I}}$

\section{RESUMEN}

Hacia fines del Periodo Intermedio Temprano e inicios del Horizonte Medio, surge un estilo innovador en la costa sur central del Perú, el estilo Cerro del Oro, cuyo nombre deriva del sitio del mismo nombre ubicado en el valle bajo de Cañete. Esta cerámica reúne formas novedosas e iconografía proveniente de diversas tradiciones.

Planteamos que el estilo cerámico Cerro del Oro no es exclusivo del valle de Cañete y se distribuye principalmente en el valle de Asia, llegando hasta Mala y Chilca. Para el valle de Asia se encuentra asociado a una serie de sitios habitacionales ubicados en ambas márgenes del valle desde el litoral hasta el valle medio. El estilo Cerro del Oro se asocia a un patrón arquitectónico, textiles de algodón y un patrón funerario diferente al que ocurre paralelamente en la costa central. Del mismo modo algunas características antropológicas parecen indicar que se trata de un grupo diferente. Consideramos que existen pues caracteristicas para establecer su identificación espacial desarrollada fuertemente en este periodo cuyo centro principal estuvo en el valle de Cañete.

Palabras Clave: Horizonte Medio, Wari, Cerro del Oro, valle de Asia, Perú

Museo Municipal Huaca Malena, Lima, Perú. E-mail: rommelangel@hotmail.com Recibido: Diciembre 2007. Aceptado: Abril 2008 


\begin{abstract}
Towards aims of the Early Intermediate Period and the beginnings of the Middle Horizon, arises an innovator style at the south central coast, the Cerro del Oro style, whose name drift of the place of the same name located in the low valley of Canete. This pottery reunites to novel forms and iconography originated on diverse traditions.

We rose that the Cerro del Oro pottery style is exclusive from $\mathrm{Ca}$ nete Valley and distributed at the valley of Asia, arriving even till Mala and Chilca. At the valley of Asia it is associated to a series of housing places located in both margins of the valley from the coast to the middle valley. The Cerro del Oro style is associated to an architectonic pattern, cotton textiles and funerary patterns which are different from the ones that appears parallels at the central coast. In the same way some anthropological characteristics seems to indicate that those people belong to a different group. We consider that there exist characteristics to establish their space identification strongly develop at this period whose main centre was located at the Cañete Valley.
\end{abstract}

Key Words: Middle Horizon, Wari, Cerro del Oro, Asia valley, Peru.

\title{
INTRODUCCIÓN
}

El Horizonte Medio constituyó una etapa crucial en los Andes Centrales. Este implicó cambios en el patrón funerario, el crecimiento de una serie de asentamientos y el desarrollo de un sistema ideológico que unificó gran parte de los Andes Centrales con sus respectivos aportes locales; estos fenómenos se evidencian en la costa y sierra a través de nuevos tipos de patrón de asentamiento, variaciones en el patrón funerario, aparición de textiles con iconos wari y nuevos estilos cerámicos. El tránsito de este complejo periodo y su transformación hacia una época donde las sociedades adquieren una personalidad particular de carácter local, es un fenómeno poco conocido.

Hacia fines del Periodo Intermedio Temprano e inicios del Horizonte Medio, surge un estilo innovador en la costa surcentral. El sitio Cerro del Oro en el valle bajo de Cañete se convierte en el centro de un movimiento 
especial plasmado en su cerámica, advertida tempranamente por Kroeber y Menzel.

A partir de los trabajos de Alfred Kroeber (1937) y Louis Stumer (1971), Dorothy Menzel (1968) definió para el Horizonte Medio la existencia de un nuevo estilo para el valle de Cañete al cual se denominó Cerro del Oro, cuyo nombre deriva del importante sitio arqueológico en el valle bajo de Cañete donde se ubica un extenso complejo arquitectónico y cementerio. El estilo Cerro del Oro toma una serie de elementos morfológicos e iconográficos de diferentes estilos como Nasca, Cajamarca, Lima, Nievería y Chaquipampa. Posteriores trabajos en el referido sitio (Ruales 2001), establecieron aspectos de la arquitectura, asociaciones y la secuencia ocupacional del sitio.

El presente trabajo, muestra que dicho estilo cerámico no es exclusivo del valle de Cañete y se distribuye principalmente en el valle de Asia, llegando hasta Mala y Chilca. Para el valle de Asia se encuentra asociado a una serie de sitios habitacionales ubicados en ambas márgenes del valle, desde el litoral hasta el valle medio. El estilo Cerro del Oro se asocia a un patrón arquitectónico, textiles de algodón y un patrón funerario diferente al que ocurre paralelamente en la costa central. Del mismo modo algunas características antropológicas parecen indicar que se trata de un grupo diferente. Consideramos que existen pues características para establecer su identificación espacial desarrollada fuertemente en este periodo cuyo centro principal estuvo en el valle de Cañete.

\section{El VALLE DE ASIA: ECOLOGÍA Y ARQUEOLOGÍA}

El valle de Asia se encuentra situado a 100 kilómetros al sur de Lima, entre los valles de Mala por el norte y Cañete por el sur (Figura 1). Destaca por su aridez, el amplio cono deyectivo y sus playas arenosas frente a la isla de Asia, donde habitan lobos de mar, y la cual constituye un importante lugar para el anidamiento de aves guaneras.

El valle es corto, no penetra más de 60 kilómetros en la sierra. Presenta suelos aluviales y un relieve que muestra depresiones. La agricultura es bastante difícil utilizándose para tal efecto el agua del subsuelo a través de pozos. Las pampas eriazas tienen poco uso por la falta de agua de riego. Los suelos tienen un origen aluvial, coluvial y eólico. La fauna es típicamente costeña. 


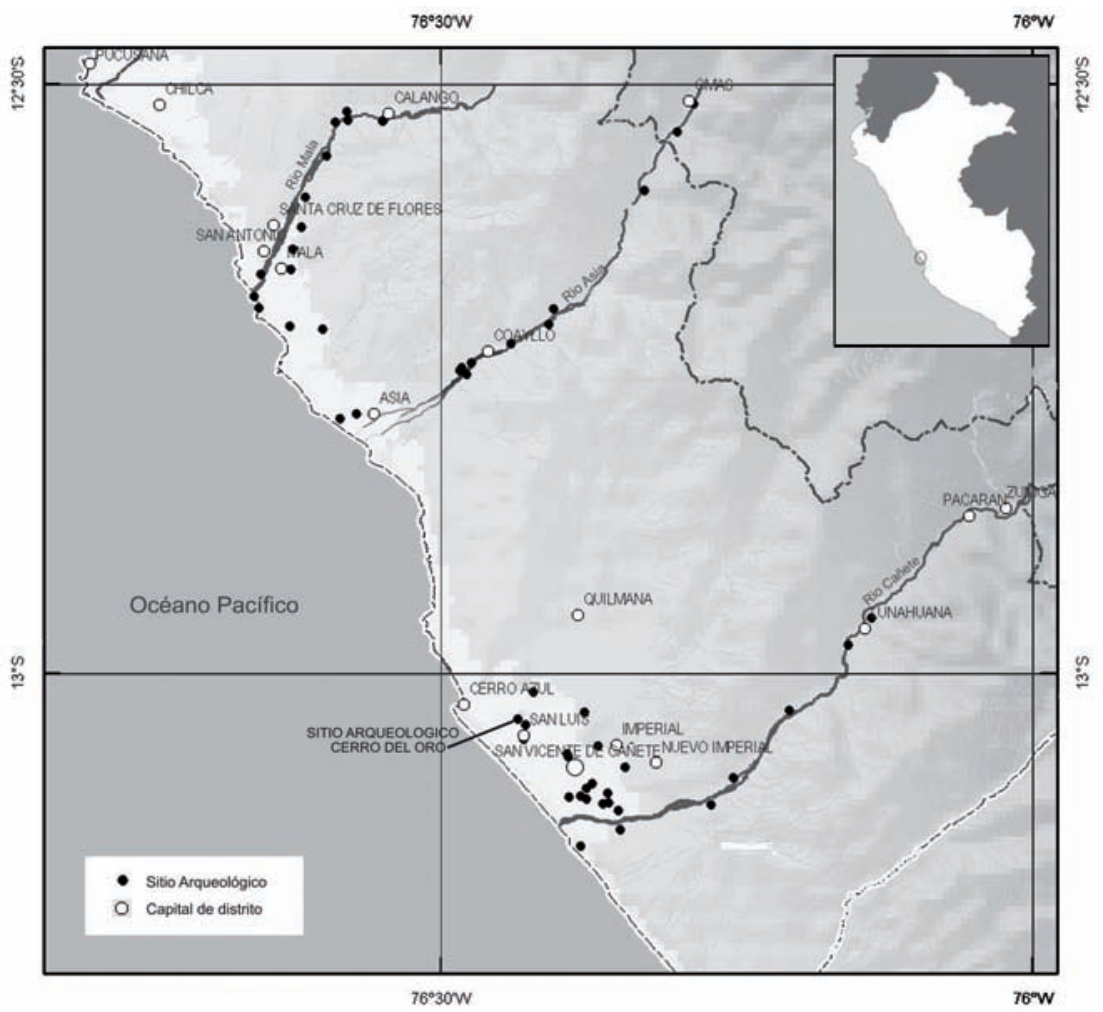

Figura 1. Mapa de ubicación de la costa sur central y el valle de Asia.

Figure 1. Map of location of the central South coast and the Asia valley.

A casi un kilómetro de la playa el cauce del río se divide en dos vertientes, las cuales son denominadas El Gallo y Río Chico.

Las lomas en la actualidad, son explotadas de manera temporal por los ganaderos de la sierra y de manera permanente para la explotación de piedras y gravilla como material de construcción por los pobladores de la costa. Estas se ubican en ambas márgenes del valle, destacando las de Puquio Salado, Marquesa, Casablanca, Pacay, Perico y El Huaranguito al norte, y las lomas de Quilmaná y Ancapuquio al sur. Estas son intensamente aprovechadas en invierno, cuando crece el pasto para el alimento del ganado que baja de la sierra aledaña.

A la altura de la localidad de Coayllo existe un puquio de agua y de las cercanías nace un canal de irrigación para el valle, y un segundo irriga la porción norte del valle. Ambos se inician casi en la misma toma (Tello 2000: 13). 
El valle medio es estrecho y de bordes pendientes, ensanchándose a la altura de las localidades de Coayllo, Uquira y Omas. Coayllo presenta un clima cálido, posee agricultura permanente, se dedica al cultivo casi exclusivo de nísperos y pacae, y en menor grado de maíz y otros frutales. Posee una baja densidad poblacional, y está dividida en los anexos de San Juan de Quisque, Coayllo, Uquira, Yesera y Esquina. Estas áreas corresponden a las de mayor productividad y a las de mayor número de sitios prehispánicos a partir del Horizonte Medio en adelante.

Un camino carrozable une Asia con Coayllo, Uquira, Omas y Quinches.

La información arqueológica del valle es escasa. Cirilo Huapaya Manco indica la presencia de una variedad de arquitectura y cerámica (Tello 2000: 179-189) reportando materiales que hoy podemos asignarlos al Periodo Intermedio Temprano, Horizonte Medio, Periodo Intermedio Tardío y Horizonte Tardío. Mejía Xesspe realiza anotaciones sobre el valle y realiza las excavaciones en Huaca Malena bajo la dirección de Julio C. Tello (Tello 2000).

Frederic Engel (Engel 1963, 1987), señala la existencia de 190 sitios (20 precerámicos, 87 chavín, 3 wari, 2 huacas post-wari: Huaca Malena y Huaca Partida, 26 poblados ica-chincha-cańete y uno con rasgos incaicos, así como 50 no determinados) (Engel 1987). Engel también realiza estudios en el sitio temprano de Asia Unidad 1, correspondiente al periodo Arcaico (Engel 1963).

Ángeles (2002) reporta un importante hallazgo del periodo Formativo, relacionándolo con el área de interacción Chavín. Dorothy Menzel (1971) describe material cerámico del Periodo Intermedio Temprano al cual denomina estilo Capilla. En 1997, Denise Pozzi-Escot dirige excavaciones en Huaca Malena reportando datos sobre el Periodo Intermedio Temprano y el Horizonte Medio (Ángeles y Pozzi-Escot 2000, 2001, 2004, 2005).

Ángeles y Pozzi-Escot (2004) realizan una síntesis acerca de la ocupación del valle durante el Periodo Intermedio Tardío hasta el Horizonte Tardío.

Sandra Negro (1982) describe el sitio inca de Uquira, el cual es investigado nuevamente por Antonio Coello (1991) y recientemente excavado por Emily Baca (2001).

En resumen, podemos indicar que la ocupación en el valle ha sido permanente, existiendo periodos de alta y baja densidad poblacional, y al respecto debe considerarse la escasez de agua durante las avenidas del río. 
Durante el periodo Precerámico Tardío, la ocupación se concentra en el valle bajo. No se conforman grandes centros ceremoniales sino áreas habitacionales y cementerios en las mismas zonas habitacionales. Durante el Periodo Inicial, crece el número de sitios habitacionales, y algunos de estos al parecer cumplirían funciones rituales, pero no aparecen grandes complejos ceremoniales como ocurre en la costa central. Durante el Horizonte Temprano se reporta una baja poblacional y un desarrollo de asentamientos importantes en el valle medio y superior a la altura de Omas. Este es un fenómeno peculiar que sucede de manera paralela en el valle de Cańete.

Durante el Periodo Intermedio Temprano se construye el sitio más extenso, Huaca Malena, y aparecen asentamientos relacionados a lo largo del valle bajo y medio, pero en número menor. Durante el Horizonte Medio, en su primera época, aparece el estilo Cerro del Oro y se produce un aumento de los asentamientos habitacionales desde el litoral hasta el valle alto. A partir de la Época 3 del Horizonte Medio hay nuevos cambios y se reportan importantes contextos funerarios en Huaca Malena.

El Periodo Intermedio Tardío corresponde al grupo denominado Coayllo, el cual ocupa principalmente el valle medio. Durante el Horizonte Tardío los sitios son ampliados y se ubican tanto en las zonas de mayor producción agrícola como también en las entradas de quebradas importantes, así como en lugares de la parte alta debido al estrecho contacto con la sierra (Ángeles 2003).

\section{El Periodo Intermedio Temprano en el Valle de Asia}

Las excavaciones realizadas en Huaca Malena (Ángeles y Pozzi-Escot 2000), permitieron caracterizar para este periodo, una arquitectura de adobes semicilíndricos hechos a mano y una cerámica tricolor caracterizada por platos de contorno simple con decoración interna. Los cántaros son de cuello recto corto, color marrón y diseños en blanco ubicados en el labio (Figura 2). Huaca Malena fue construida durante este periodo constituyendo el sitio más destacado del valle de Asia para esta época. Los reconocimientos llevados a cabo en el valle indican a su vez la presencia de 10 sitios contemporáneos que comparten similar arquitectura y cerámica. Esta cerámica y arquitectura ha sido reportada también en el valle de Mala (Gabe 2000) para el sitio denominado Cerro Salazar, también conocido como Totoritas. Nuestros reconocimientos indican la presencia de esta cerámica en el sitio de San José del Monte en Mala (Ángeles 2003) así como en los niveles inferiores de Cerro del Oro en el valle de Cañete, de acuerdo a la información publicada por Mario Ruales (2001). Por lo expuesto, podemos plantear que durante el Periodo Intermedio 
Temprano los valles de Mala, Asia y Cañete estuvieron relacionados tanto a nivel de arquitectura como de cerámica, pero sus lazos sociales, económicos y políticos aún no pueden ser definidos. Es evidente que se trata sin embargo de la primera evidencia de cohesión cultural que se presenta para dichos valles, sin descartar que futuras investigaciones aclaren las probables relaciones que habrían existido durante el Horizonte Temprano.

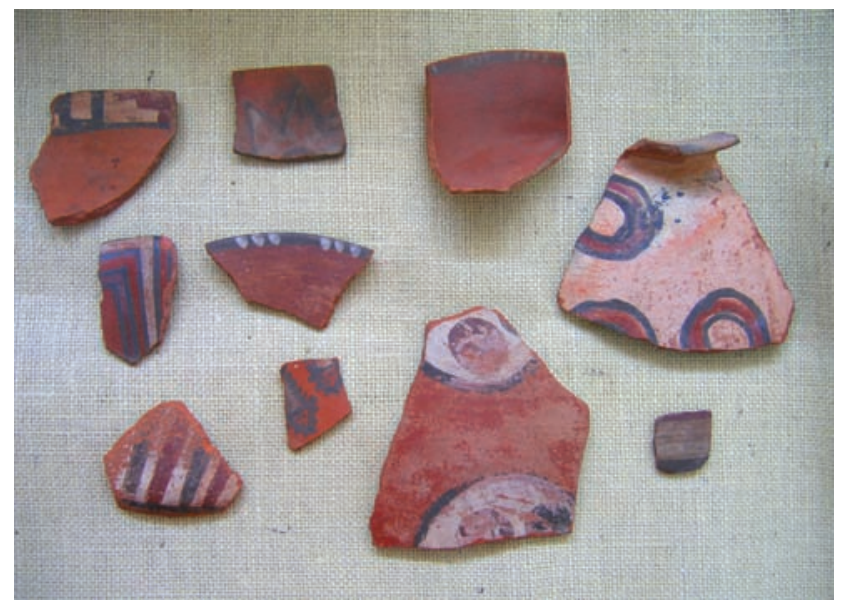

Figura 2. Cerámica del Periodo Intermedio Temprano procedente de Huaca Malena. Colección Museo Municipal Huaca Malena.

Figure 2. Ceramics of the Early Intermediate Period from Huaca Malena. Collection Municipal Museum Huaca Malena.

El Horizonte Medio: Épocas 1 y 2

De acuerdo a Menzel, la Época 1 del Horizonte Medio para el valle de Cañete se caracteriza por la aparición del estilo Cerro del Oro, cuyo nombre deriva del extenso complejo ubicado en el valle bajo de Cañete (Kroeber 1937). Se trata de un estilo que condensa diversos estilos propios del Horizonte Medio que son comunes en Lima, Nasca, Ayacucho e inclusive Cajamarca.

El reconocimiento del valle bajo y medio de Asia nos ha permitido identificar cerámica del estilo Cerro del Oro en el valle bajo así como en ambas márgenes del valle de Asia hasta la localidad de Omas. Ejemplares similares a los reportados por Kroeber (1937) y Ruales (2001) en Cerro del Oro, están presentes en el valle de Asia pero en esta ocasión se encuentran asociados a terrazas habitacionales. Una característica importante es el aumento de población, el uso intensivo de terrazas aglutinadas a ciertos sectores del valle e inclusive una fuerte comunicación y relación con el valle de Mala. 
Durante la época 1 del Horizonte Medio, Huaca Malena es abandonada. Efectivamente, en el lugar solo han sido hallados escasos fragmentos de cerámica de estilo Cerro del Oro y hay una ausencia total de arquitectura de adobes cúbicos hechos a mano.

\section{La Cerámica del Estilo Cerro del Oro}

De acuerdo a Dorothy Menzel (1968: 101-103), el estilo Cerro del Oro es muy ecléctico, con características prestadas de una variedad de otras tradiciones estilísticas, incluyendo Nievería, Nasca 9 y Chaquipampa. Hay también algunos elementos que representan supervivencias de la tradición Lima de la costa central y que datan de las épocas precedentes. Algunas de las características más notables del estilo Cerro del Oro las encontramos en una alfarería de pasta notablemente blanca o amarillenta, y escudillas con base anular, características estas que no tienen semejanza con ninguno de los estilos del Horizonte Medio 1, ni anteceden en ninguna de las tradiciones costeñas. Los estudios del estilo están basados principalmente en la cerámica procedente de las excavaciones realizadas por Alfred Kroeber (Figuras 3, 4, $5)$.

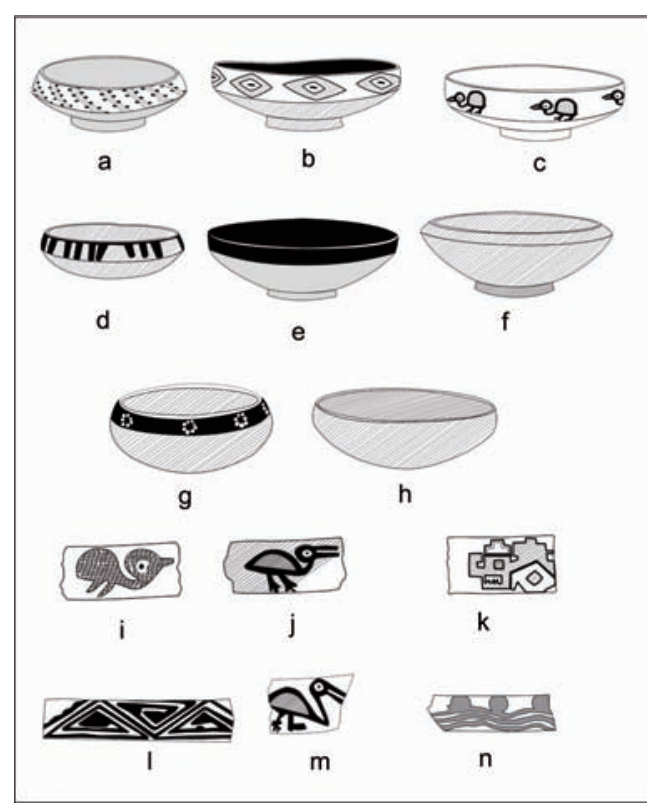

Figura 3. Platos de estilo Cerro del Oro procedentes de las excavaciones de Alfred Kroeber en Cerro del Oro (1937), similares al material de los valles de Asia y Mala.

Figure 3. Plates of Cerro del Oro style coming from the excavations of Alfred Kroeber in Cerro del Oro (1937), ceramics similar from Asia and Mala valleys. 
Las escudillas con base anular son el tipo de vaso más común en el estilo Cerro del Oro, y también son comunes cántaros de tamaño grande, mediano y pequeño. Otro tipo común son las escudillas toscas, la mayoría de las cuales son muy similares a las del estilo Nasca 9. Las coladeras cónicas son únicas. Algunos diseños de aves y cabezas trofeo tienen marcada semejanza con el estilo Nasca 9. Aparecen así mismo, diseńos nievería, especialmente las escudillas de base anular, siendo el tipo más común el animal encorvado del estilo Nievería y una pequeña variante especial del animal con aguijón, extendido ventralmente, también del estilo Nievería. Algunos de los diseños de la tradición Lima también se presentan en Nievería y Cerro del Oro. El estilo Cerro del Oro tiene además una variante modificada del animal encorvado, tema que está presente en todos los estilos del Horizonte Medio. Hay también imitaciones locales que derivan de los diseños chaquipampa, tales como los diseños de rayos con simetría rotacional y rayos prolongados con tallos ondulantes y un animal extendido de cúbito ventral con cuerpo trapezoidal que es atribuido específicamente al estilo Chaquipampa B.

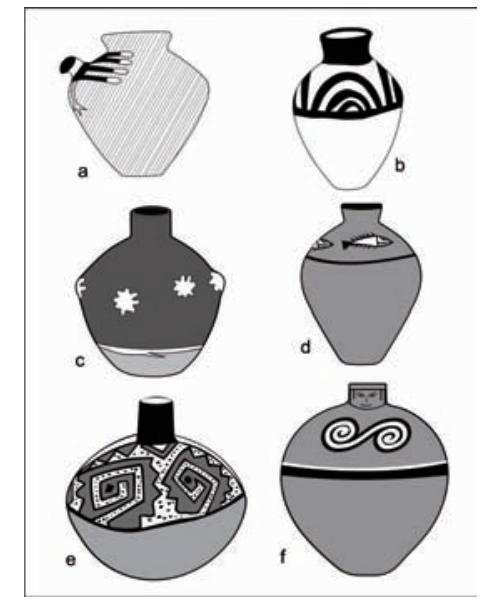

Figura 4. Cántaros de estilo Cerro del Oro, procedentes de las excavaciones de Alfred Kroeber en Cerro del Oro (1937).

Figura 4. Jars Cerro del Oro style, coming from the excavations of Alfred Kroeber in Cerro del Oro (1937).

Según Menzel (1971: 132-133), las innovaciones más importantes del estilo Cerro del Oro son: el cuenco de ángulo basal con lados cortos y fondo profundo, por lo general con base anular (Kroeber 1937: LXXI), y el uso de nueva arcilla blanca caolín. Tanto la forma del vaso como el uso de la pasta blanca recuerdan al estilo Cajamarca, especialmente en su fase II. También aparecen algunos nuevos diseños que son casi idénticos a los diseños de Cajamarca II, notablemente una greca escalonada negra sobre fondo blanco 
dentro de una banda angosta, la cual algunas veces bordea el diseño del perfil de un animal encorvado. La única diferencia es que el diseño del animal encorvado del estilo Cerro del Oro es parecido al del estilo Nievería.
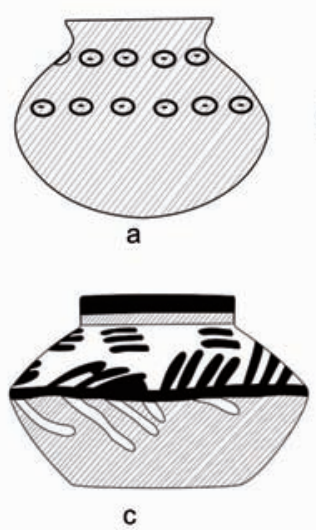
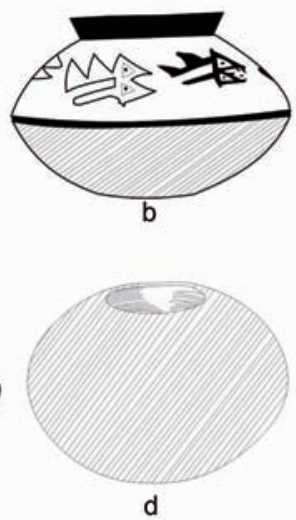

Figura 5. Ollas de estilo Cerro del Oro procedentes de las excavaciones de Alfred Kroeber en Cerro del Oro (1937).

Figure 5. Pots Cerro del Oro style coming from the excavations of Alfred Kroeber in Cerro del Oro (1937).

Las semejanzas más próximas a Nasca 9 se refieren a cuencos pesados idénticos a los de Nasca 9 de Ica y Nasca, diseños de cabezas trofeo y diseños de rayos, especialmente aquellos de animales encorvados con apéndices radiales, que pertenecen al estilo Nievería, y otros que pertenecen a la tradición de diseño de rayos de Ayacucho, notablemente con la presencia de rayos con tallos ondulados, un diseño de animal encorvado con cola larga y en espiral, y figuras de rayos bilateralmente simétricos. Pueden ocurrir también rasgos serranos como diseños radiales de rotación, figuras similares a palanquetas de gimnasia y grandes bandas en zigzag que pertenecen a la variedad Acuchimay Polícromo de Bennett.

De acuerdo a Menzel, tanto su eclecticismo como lo asombroso de su mezcla son característicos de toda una serie de estilos de prestigio del Horizonte Medio 1 de la costa sur, la costa central y la sierra.

En Chincha, Dwight Wallace halló cerámica relacionada al estilo Cerro del Oro en PV 57-26 y 48. Kroeber reporta cerámica Cerro del Oro en el valle de Mala (Kroeber 1937).

Menzel asevera (1971: 135) que la significación del estilo Cerro del Oro está en que probablemente representa la única época en la historia de 
Cañete cuando este valle y Asia compartieron un estilo especial de prestigio propio, en el cual lograron combinar una selecta mezcla de rasgos de estilos de todas partes del Perú, formando un modelo original. Por esta razón el área de Cañete-Asia es un importante campo nuevo para el estudio de los patrones de difusión del Horizonte Medio. Uno se pregunta cuál será la explicación de su breve independencia.

Todos los estilos de prestigio regional del Horizonte Medio 1 tuvieron una corta existencia y, con la excepción de algunos vasos, sobrevivieron apenas rastros de ellos en las épocas siguientes. La explicación de esto radica probablemente no sólo en el hecho de que fueron en su mayoría mezclas basadas en tradiciones extranjeras, sino también en que fueron estilos esencialmente seculares que no parecían tener ninguna significación simbólica particular. Evidentemente, ambos factores fueron en parte responsables de la rápida suplantación de los estilos del Horizonte Medio 1 por los nuevos estilos de prestigio tiahuanacoides de Wari y Pachacamac que tenían una gran cantidad de rasgos simbólicos, además de los seculares, y quizás de mayor importancia es el hecho de que contribuyeron con ideas originales y no hicieron simplemente mezclas de rasgos prestados.

\section{El sitio Cerro del Oro}

Se encuentra ubicado a la altura del Kilómetro 136 de la carretera Panamericana Sur, en el distrito de San Luis, provincia de Cańete. De acuerdo a Mario Ruales, el sitio ocupa un área aproximada de 120 hectáreas, compuesto por una serie de estructuras piramidales, plazas, recintos y plataformas levantadas con adobes cúbicos hechos a mano, un segundo sector tardío compuesto por recintos de tapia asociados a cerámica Cañete Último y Chincha así como una serie de estructuras de piedra y cementerios del mismo periodo.

\section{Investigaciones Previas}

Los trabajos realizados por Alfred Kroeber en 1925 permitieron establecer las características de la arquitectura y la cerámica. Posteriormente Julio C. Tello realizó excavaciones en el lugar y los materiales recuperados en estos trabajos se conservan en el Museo Nacional de Arqueología, Antropología e Historia del Perú (Figuras 6, 7). 

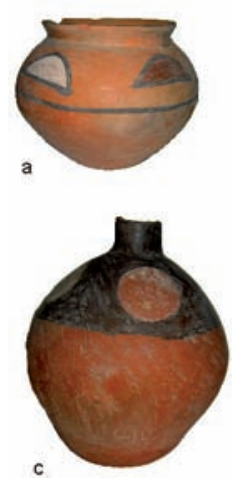
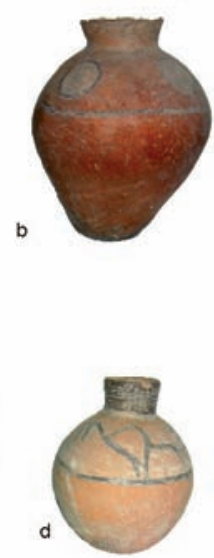

Figura 6. Cerámica procedente de Cerro del Oro, Cañete. Colección Tello (Museo Nacional de Arqueología, Antropología e Historia del Perú).

Figure 6. Ceramics coming from Cerro del Oro, Cañete. Collection Tello (National Museum of Archaeology, Anthropology and History of Peru).

A fines de la década de 1950, Louis Stumer (1971) realiza estudios y define el estilo Cerro del Oro como perteneciente al Periodo Intermedio Temprano e inicios del Horizonte Medio.

Menzel (1968) determina que el estilo Cerro del Oro pertenece a la Época 1 del Horizonte Medio, principalmente por rasgos de la cerámica que recuerda a diseños chaquipampa y nasca 9 .

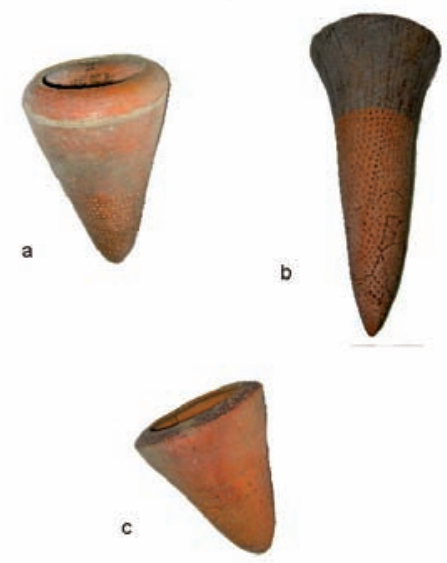

Figura 7. Cerámica procedente de Cerro del Oro, Cañete. Tipos de coladores. Colección Tello (MNAAHP).

Figure 7. Ceramics coming from Cerro del Oro, Cañete. Types of strainers. Collection Tello (MNAAHP). 
De acuerdo con Mario Ruales (2001), el sitio presenta dos ocupaciones, una del Periodo Intermedio Temprano con presencia de adobes semicilíndricos y una segunda etapa con adobes cúbicos y la cerámica denominada Cerro del Oro.

\section{El estilo Cerro del Oro en el valle de Asia}

Las características formales del estilo reportado en el sitio de Cerro del Oro, nos permiten establecer las características morfológicas y decorativas para distinguirlo estableciendo sus asociaciones a arquitectura, patrón de asentamiento y otros materiales culturales.

Las características del estilo Cerro del Oro presentes en los materiales del valle de Asia, son casi idénticas a las del valle de Cañete, tanto a nivel morfológico como decorativo. Se presentan:

1) Platos de color naranja natural decorados con una banda negra gruesa en el borde interior.

2) Cuencos de paredes altas y divergentes y labio redondeado.

3) Cuencos con paredes verticales rectas o muy ligeramente convexas, bases inclinadas, rectas y con base anular (Figura 8).

4) Decoración externa con diseños serpentiformes, animal encorvado, cabezas antropomorfas, grecas o color crema verdoso. Diseńos en color crema, rojo, naranja, gris o violáceo oscuro.

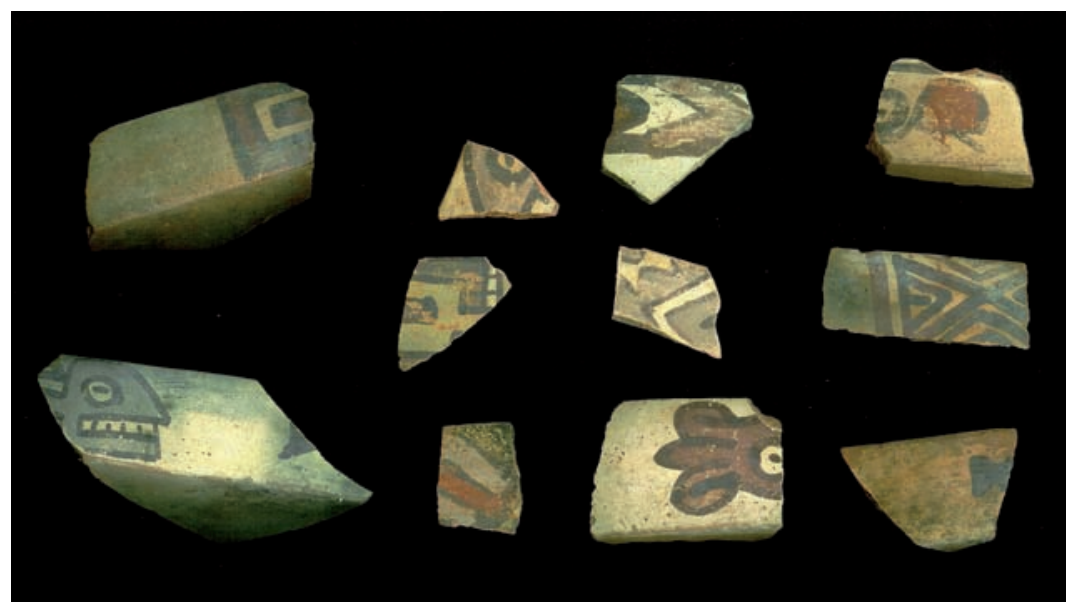

Figura 8. Platos con ángulo basal de estilo Cerro del Oro, procedentes de Topas o Quisque 2, valle medio de Asia. Colección Museo Municipal Huaca Malena. Figure 8. Plates with basal angle of Cerro del Oro style, coming from Topas or Quisque 2, average valley of Asia. Collection Municipal Museum Huaca Malena. 
5) Acabado alisado mate.

6) Jarras pequeñas, medianas y grandes.

7) Cántaros. El cuello supera la altura del cuerpo. Generalmente no están decorados en el cuello a excepción de bandas en negro, marrón o violáceo sobre naranja natural.

8) Decoración geométrica en el cuerpo (incluye círculos con asterisco) o aspas múltiples al interior, diseńos triangulares, círculos delineados en negro. En varios casos los cántaros presentan cuello efigie relacionado a materiales de Nasca.

9) Ollas escasas, globulares y de cuello corto ligeramente expandido.

10) Coladores, de forma cónica con borde doblado al interior, decoración en el tercio superior generalmente de color negruzco o violáceo, pocos ejemplares presentan diseños estilizados. Existe variación en el tamaño de los agujeros del colador.

\section{Decoración}

1) Espirales y figuras en $S$ decoradas con puntos blancos tanto en el borde como en el interior, generalmente en el tercio superior de las vasijas.

2) Diseños antropomorfos de un personaje de perfil.

3) Rostros humanos en los platos similares a las cabezas trofeo nasca que aparecen también como cara-gollete en jarras y en las figurinas que recuerdan al estilo Nasca.

4) Animal encorvado (variante del estilo Nievería) según Menzel (1968). Es muy común en varios tipos de vasijas.

\section{Componentes morfológicos}

1) Platos de ángulo basal.

2) Platos con decoración interna.

3) Cántaros (Figura 9).

4) Cántaros cara-gollete.

5) Coladores cónicos.

6) Figurinas de la tradición Nasca. 
Los platos presentan base anular, paredes rectas de labio adelgazado, decoración externa, fondo crema con una banda delgada de color negra en el labio, el resto del cuerpo presenta diseńos geométricos. Platos de paredes convergentes cortas y base redondeada. Decoración externa de triángulos con barras al interior.

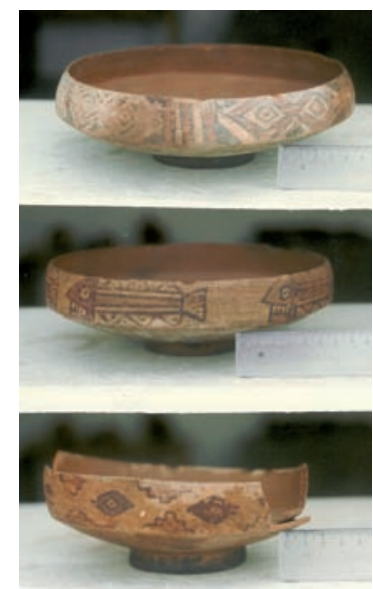

Figura 9. Cerámica de estilo Cerro del Oro asociada, procedente de contexto funerario recuperado de Quisque 2. Colección Museo Municipal Huaca Malena.

Figure. 9. Ceramics of Cerro del Oro style, coming from recovered funeral context of Quisque 2. Collection Municipal Museum Huaca Malena.

\section{Decoración}

1) Diseños de cabezas trofeo, aves en posición de perfil.

2) Diseños Nievería.

3) Animal encorvado.

4) Elementos lima similares a los utilizados por el estilo Nievería.

5) Imitaciones del estilo Chaquipampa.

6) Animal extendido de cúbito ventral con cuerpo trapezoidal.

\section{Distribución de sitios}

La distribución de la cerámica de estilo Cerro del Oro para el valle de Asia se extiende desde el litoral (sitio Las Palmas), hasta Esquina de Omas, es decir hasta los 800 metros sobre el nivel del mar aproximadamente. Aparece asociada a asentamientos discretos distribuidos en ambas márgenes del 
valle ocupando pequeñas quebradas laterales, concentrándose al pie y en las laderas de importantes cerros. Estos sitios tienen características domésticas debido a la presencia de ceniza, conchas y por la presencia de asentamientos aterrazados con arquitectura de piedra y adobes cúbicos. Alguno de estos sitios ostentan claras evidencias de contener cementerios.

En este sentido las características del estilo Cerro del Oro pueden caracterizarse en:

a) Presencia de cerámica de estilo Cerro del Oro típico de Cañete en superficie o en los perfiles expuestos al interior del valle de Asia.

b) Sitios con arquitectura de piedra de cerro conformando estructuras habitacionales ubicadas en terrazas asentadas en las laderas de cerros o en pequeñas quebradas.

c) Presencia de adobes cúbicos hechos a mano, similares a los reportados en el sitio de Cerro del Oro en Cañete, los cuales se colocan sobre los muros de piedra.

\section{Sitios en el litoral}

Destaca el sitio Las Palmas, ubicado a la altura del Kilómetro 101 de la carretera Panamericana Sur. Se trata de un conjunto de estructuras de piedra y montículos de baja altura situados en las inmediaciones de hoyas de cultivo y muy cerca de la playa arenosa. La cerámica en el sitio incluye platos de ángulo basal y base anular así como coladores. Las Palmas es el sitio más cercano al litoral, al parecer forma parte del sitio denominado El Antival por Cirilo Huapaya (Tello 2000: 185-187), donde se reporta la presencia de adobitos hechos a mano. El lugar probablemente estuvo relacionado a la explotación marina, sin embargo, su relación a hoyas de cultivo podría indicar que esta práctica agrícola podría datar de ese periodo. Las Palmas es hasta el momento el único sitio de este periodo en el litoral. El avance urbano suscitado en el litoral de Asia ha propiciado la desaparición de algunos sitios de este periodo.

\section{Sitios en el valle}

Los sitios que presentan cerámica Cerro del Oro comienzan a distribuirse en ambas márgenes del valle, a partir del estrechamiento del mismo, en las inmediaciones de la localidad de Esquina de Asia. Se trata de asentamientos de carácter habitacional mayormente discretos, ubicados de manera conglomerada al pie de algún cerro importante, o en pequeñas quebradas a ambas márgenes del valle. 
La cantidad de sitios conteniendo cerámica del estilo Cerro del Oro es alta si se compara con aquellos del Periodo Intermedio Temprano. En algunos casos reocupan sitios del periodo anterior y en otros se asientan en lugares donde antiguamente no fueron utilizados. Los sitios por lo general aparecen concentrados en las laderas de importantes cerros y en pequeñas quebradas. La zona de mayor concentración de sitios corresponde al actual distrito de Coayllo, entre los 200 y 800 metros sobre el nivel del mar. El sitio Topas o Quisque 2 destaca por su complejidad, así como la presencia de contextos funerarios con cerámica de estilo Cerro del Oro (Figura 9). Los platos de ángulo basal son sumamente populares. Del referido sitio proceden una serie de cántaros típicos de este estilo (Figuras 10, 11, 12).

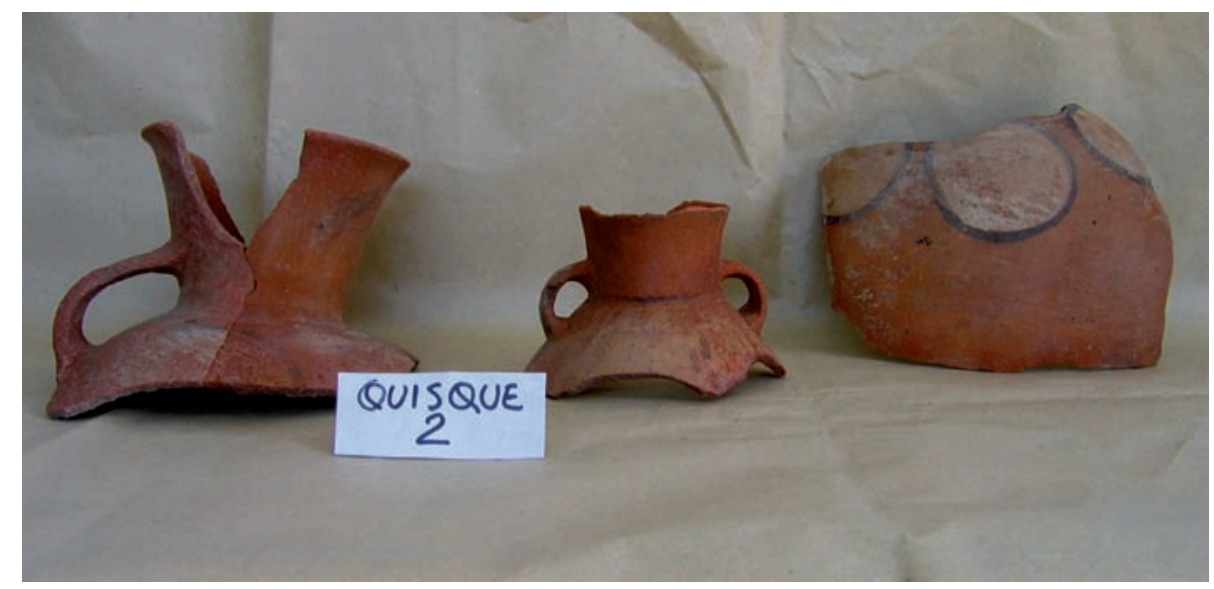

Figura 10. Cántaros de estilo Cerro del Oro, procedentes de Topas o Quisque 2, valle medio de Asia. Colección Museo Municipal Huaca Malena.

Figure 10. Pitchers of Cerro del Oro style, coming from Topas or Quisque 2, average valley of Asia. Collection Municipal Museum Huaca Malena. 


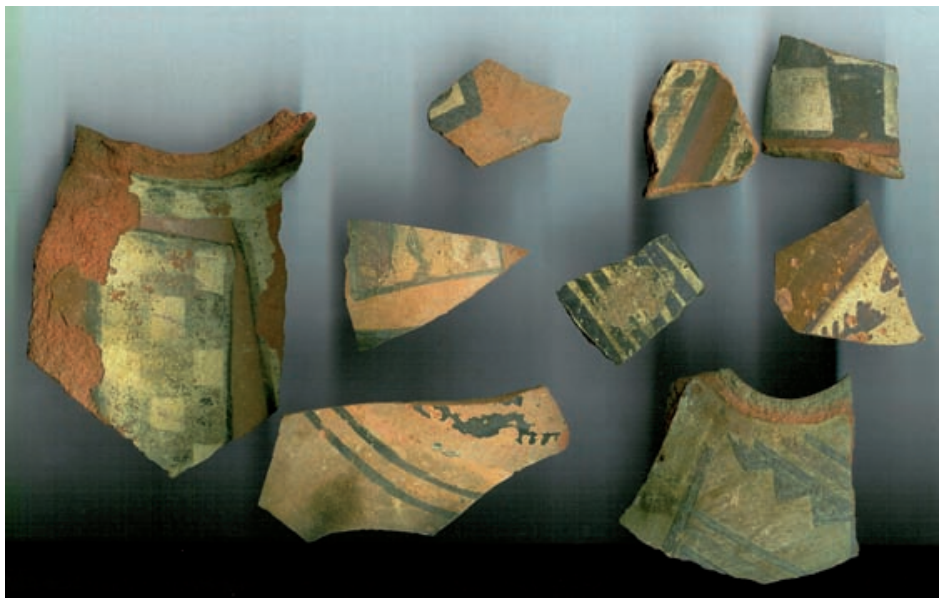

Figura 11. Fragmentos de cántaros de estilo Cerro del Oro, procedentes del valle medio de Asia. Colección Museo Municipal Huaca Malena.

Figure 11. Fragments of pitchers of Cerro del Oro style, coming from the average valley of Asia. Collection Municipal Museum Huaca Malena.

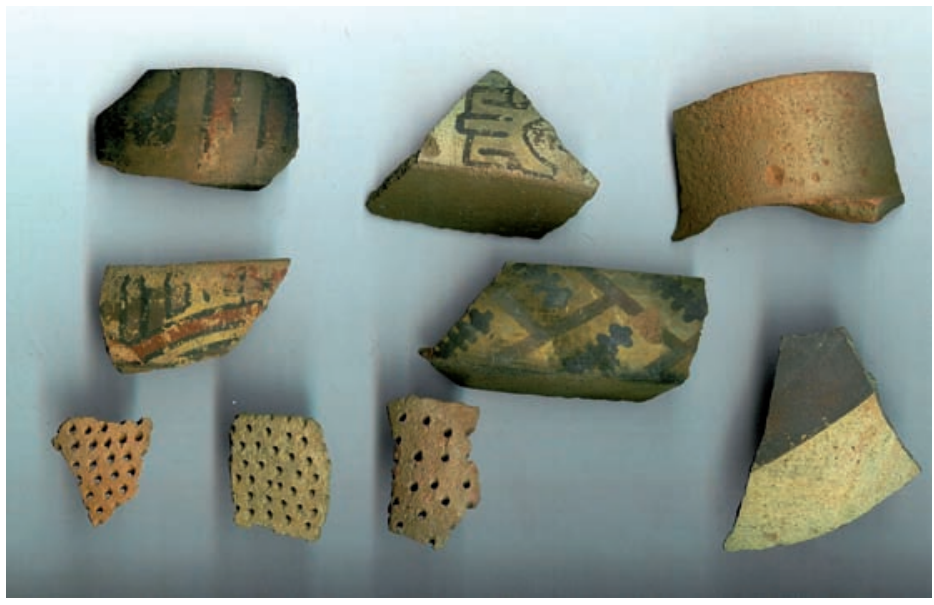

Figura 12. Cerámica Cerro del Oro: platos, cántaros y coladores. Procedentes del valle medio de Asia. Colección Museo Municipal Huaca Malena.

Figure 12. Plates, pitchers and strainers. Coming from the average valley of Asia. Collection Municipal Museum Huaca Malena. 


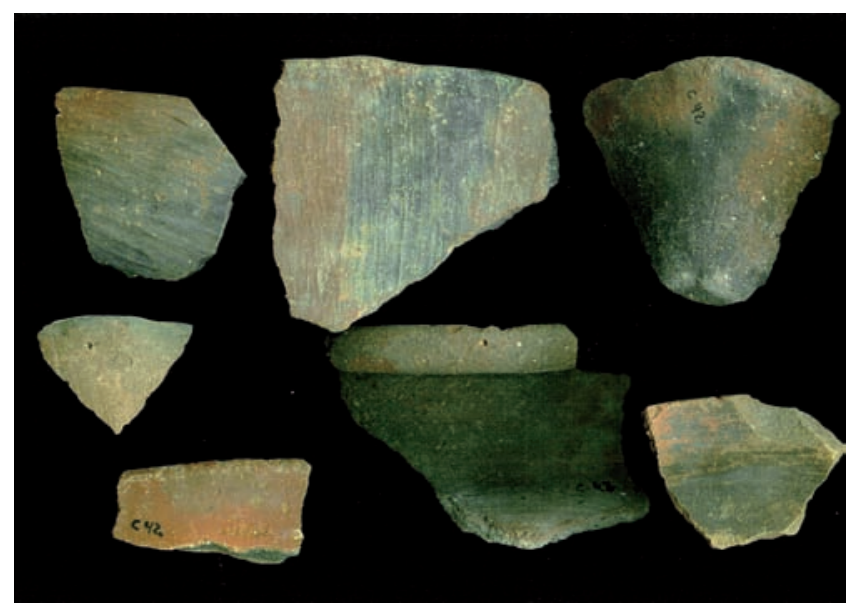

Figura 13. Cerámica llana asociada a la clásica cerámica Cerro del Oro, correspondiente a las primeras fases del Horizonte Medio. Colección Museo Municipal Huaca Malena.

Figure 13. Ceramics associated to the classic ceramics Cerro del Oro, corresponding to first epochs from the Middle Horizon. Collection Municipal Museum Huaca Malena.

En la figura 1 se ilustra la relación de los principales sitios arqueológicos de este periodo que presentan cerámica Cerro del Oro en superficie. Como se aprecia aparecen desde el litoral y ocupan hasta el valle medio. Asociado al fino estilo Cerro del Oro aparece una cerámica llana de superficie alisada tosca de color marrón con huellas de estrías verticales; bowls, cántaros de labios engrosados, coladores en forma de bowl, platos y miniaturas conforman su hábeas morfológico (Figura 13). Si bien la mala conservación de los sitios no permite apreciar sus características formales, algunos de ellos permiten comprender mejor su organización espacial (Figura14).

\section{Caracterizando la distribución del estilo Cerro del Oro en el Valle de Cañete}

Si bien el sitio Cerro del Oro es el asentamiento más extenso y en el cual se definió este estilo cerámico (Kroeber 1937, Menzel 1968, 1971; Ruales 2001), la distribución de sitios es más amplia en el valle de Cañete.

El sitio Cerro del Oro se caracteriza por presentar arquitectura masiva de adobes cúbicos hechos a mano que conforman grandes recintos, tumbas abovedadas y de acuerdo a la información de Ruales, existen evidencias de paredes que contenían frisos con diseños relacionados a la cerámica de este estilo. 


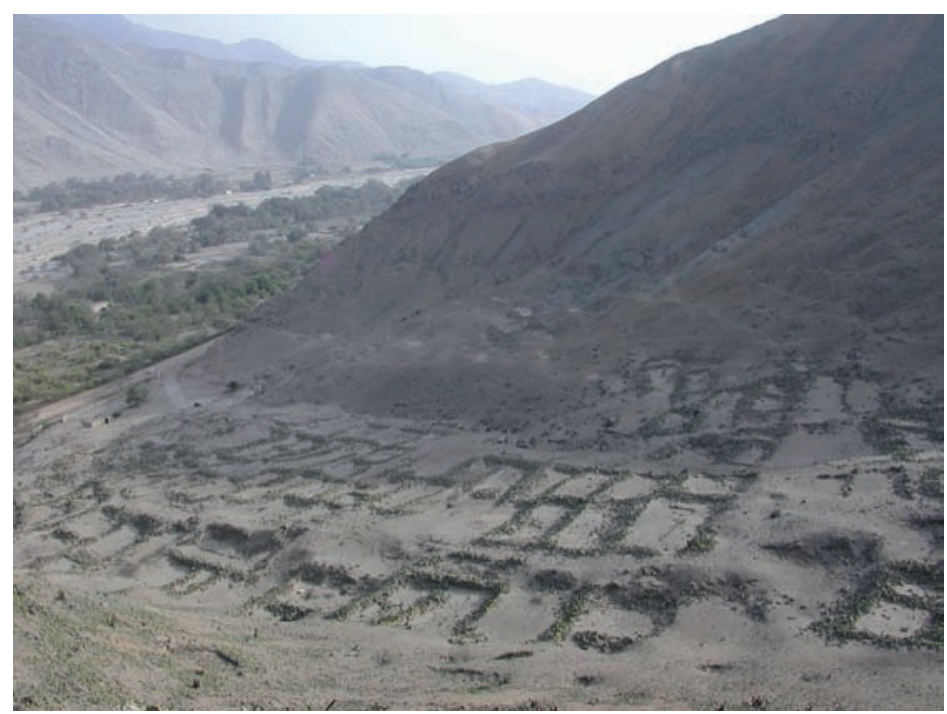

Figura 14. Uno de los sitios que integran el grupo de asentamientos al pie de Cerro Las Papas.

Figure 14. One of the sites that integrate the group of establishments on the Hill Las Papas.

En el valle bajo de Cañete, en el lugar denominado Pampa Clarita, en los terrenos de la empresa Agriconsa, el sector ubicado entre Herbay Alto y Concón, en el brazo izquierdo del valle y cerca de la desembocadura del río, Héctor Walde (Comunicación personal) reportó el hallazgo de un cementerio con una serie de contextos funerarios conteniendo fardos asociados a cerámica Cerro del Oro. Se trataba de contextos funerarios en forma de bota con una boca de 120 centímetros y una profundidad de 3 a 4 metros. Los individuos se hallaban enfardelados y poseían tocados en la cabeza. Fueron recuperados tres fardos funerarios y diversos materiales tales como penachos de plumas y diversos adornos sumamente finos. Estos materiales se encuentran depositados en el Museo Nacional de Arqueología, Antropología e Historia del Perú.

De la localidad de San Vicente de Cañete en el sector La Balanza, procede un cántaro de cuello recto de color marrón y decoración de bandas paralelas y círculos concéntricos en la parte superior del cuerpo. Esta vasija se inserta dentro del estilo Cerro del Oro (Figura 15). 


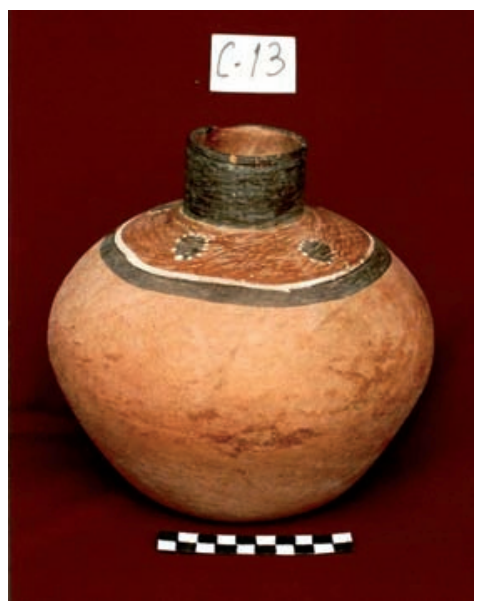

Figura 15. Cerámica de estilo Cerro del Oro, procedente de La Balanza, valle bajo de Cañete. Colección Museo Municipal Huaca Malena.

Figure 15. Ceramics from La Balanza, lower Cañete valley. Collection Municipal Museum Huaca Malena.

Durante labores de prospección en el valle medio de Cañete en la localidad de Lunahuana, Juan Paredes reportó el hallazgo de una gran piedra a manera de huanca enmarcada dentro de una estructura cuadrangular de adobes cúbicos a manera de adoratorio. En el lugar pudimos observar la presencia de cerámica Cerro del Oro así como evidencias de pintura mural sobre una pared blanca con diseños estilizados delineados en negro y rojo. El sitio fue bautizado por Juan Mogrovejo como Huanca Maki debido a que la piedra posee unas horadaciones naturales a manera de garra de felino. Sus coordenadas UTM son 361665 E y 48904 N.

El importante trabajo de identificación de sitios arqueológicos del valle de Cañete realizado por Carlos Wiliams y Francisco Merino (1974), muestran una serie de sitios en el valle con cerámica de este estilo (Figura 1).

Como se percibe, existen una serie de sitios de diferente tipo que se distribuyen entre el litoral, el valle bajo y el valle medio de Cañete. La mayor parte de sitios son aldeas, aunque existen sitios de probable carácter administrativo y religioso.

\section{LA CERÁmica DE LA COLECCión TELLO}

El Museo Nacional de Arqueología, Antropología e Historia del Perú conserva una colección de cerámica, procedente del sitio de Cerro del Oro. De acuerdo al año de registro esta pertenecería a la colección realizada por 
Julio C. Tello en 1925 (Figuras 6, 7). Está compuesta por una olla (C 34255 22.7) con el labio delineado en marrón oscuro, cuello corto evertido y cuerpo globular color naranja, tiene una altura de 24 centímetros y la boca posee un diámetro de 24 centímetros. Presenta decoración en la parte superior del cuerpo con diseños de media luna en posición horizontal delineados en negro y al interior presenta color blanco o rojizo, el diseño es derivado de Nasca. De acuerdo a la información proporcionada por el museo, esta vasija procede del Cementerio 2-Tumba 7 de Cerro del Oro. Un tiesto de similares características procede de San José del Monte en el valle de Mala.

El primer cántaro (C 34256 22.4) es de cuello corto y ligeramente evertido, cuerpo de forma irregular y base plana, tiene una altura de 32 centímetros y una boca de 15 centímetros. La decoración en el tercio superior del cuerpo de la vasija es delimitada por una banda delgada de color negro amarronado. Presenta diseños circulares delineados en negro. Posee engobe naranja oscuro. Esta vasija recuerda a material de Mala procedente de Cerro Salazar (Gabe 2000). El segundo (C 34257 22.2) corresponde a un cántaro alto de cuello recto y corto, cuerpo globular y base plana. El material de la Colección Tello es sumamente interesante, y los coladores cónicos pertenecen al estilo Cerro del Oro al igual que uno de los cántaros. Sin embargo los otros cántaros se relacionan a material del Periodo Intermedio Temprano vinculándose fuertemente con el contexto funerario recuperado por Carmen Gabe en Cerro Salazar.

\section{El estilo Cerro del Oro en el Valle de Mala}

Dos contextos resultan de interés para establecer la presencia del estilo Cerro del Oro en el valle de Mala: las estructuras de adobes cúbicos y la cerámica reportada por Carmen Gabe en Cerro Salazar (Gabe 2000), y también la colección del colegio de Santa Rosa obtenida durante la construcción del mismo. Ambas son del valle bajo. Existen reportes de pequeños asentamientos tanto en otros sectores del valle bajo como El Salitre, en la desembocadura del río Mala, en la zona de Bujama y en Esquivilca. Otros sitios se hallan en el valle medio. Tal es el caso de San José del Monte. Se adjunta una relación de sitios reportados por Williams donde se ha reportado cerámica de este estilo.

En el sector de Bujama existe un sitio con cerámica Cerro del Oro, el cual se halla asociado a un canal de regadío producto de la ampliación de la frontera agrícola. Estaríamos hablando de poblaciones altamente organi- 
zadas que expandieron la frontera agrícola y estuvieron intercomunicadas fuertemente.

No podríamos decir que existe una jerarquía de sitios en el valle de Mala, pues las evidencias están relacionadas a zonas habitacionales y no se distinguen centros administrativos de importancia.

La colección del colegio (Figuras 16, 17), procede de contextos funerarios en los cuales predominaban fardos. Este dato resulta interesante porque se relaciona a los contextos funerarios de Cerro del Oro y Pampa Clarita en el valle de Cañete y se establecen las diferencias con los contextos funerarios contemporáneos de Nievería que se caracterizan por un patrón funerario extendido. La colección incluye cántaros de cuello recto y cuerpo globular con decoración en el tercio superior, platos con base anular y otros con decoración interna. De igual manera con anterioridad (Ángeles 2003) llamamos la atención sobre el sitio denominado San José del Monte, donde aparece un sitio de carácter habitacional con cerámica Cerro del Oro (Figura 18). Finalmente, del valle de Mala, sector de Azpitia, procede un singular hallazgo de sartas con cuentas de piedra y concha a manera de quipus asociados a agujas de hueso y madera (Figura 25) que corresponde al Horizonte Medio al relacionarse a agujas y cuentas procedentes de Cerro del Oro (Mario Ruales, comunicación personal).

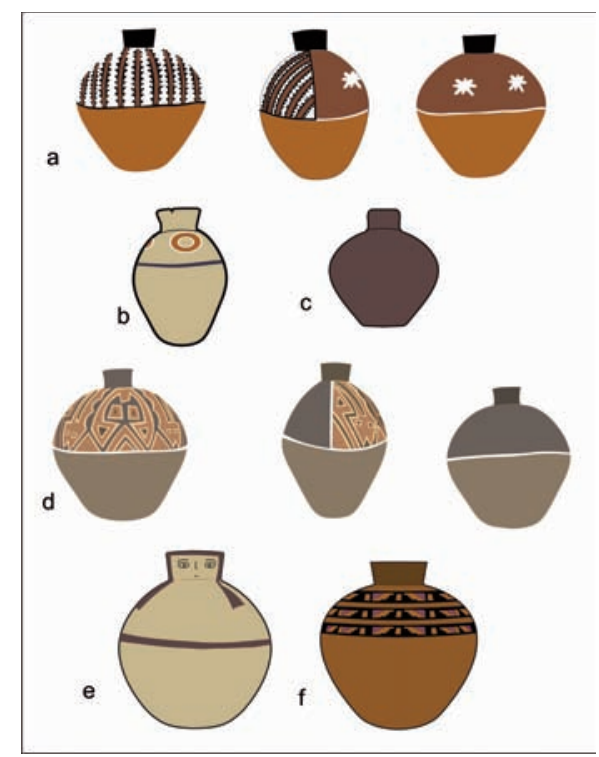

Figura 16. Cántaros de estilo Cerro del Oro, procedentes de Santa Rosa, valle de Mala. Colección Colegio Santa Rosa de Mala.

Figure 16. Pitchers Cerro del oro style from Santa Rosa, Mala valley. Collection School Santa Rosa de Mala. 


\section{Aproximaciones}

El estilo Cerro del Oro como vemos, se distribuye ampliamente entre los valles de Mala, Asia y Cańete y se asocia a arquitectura de adobes cúbicos hechos a mano y mampostería de piedra. Los sitios de mayor dimensión se ubican en el valle de Cañete donde destaca el sitio de Cerro del Oro. Sin embargo, estudios posteriores podrían determinar una jerarquía de sitios. Al parecer la aparición de este estilo se produce a fines del Periodo Intermedio Temprano y se desarrolla en la Época 1 del Horizonte Medio, cuando cobra un inusual auge. Su iconografía se alimenta de elementos foráneos, principalmente sureños y serranos así como de la costa central. La cantidad de sitios reportados principalmente en el valle de Asia indican que en esta época hubo un incremento de la población y, en consecuencia, pudieron suscitarse cambios climáticos que favorecieron el desarrollo de actividades agrícolas.

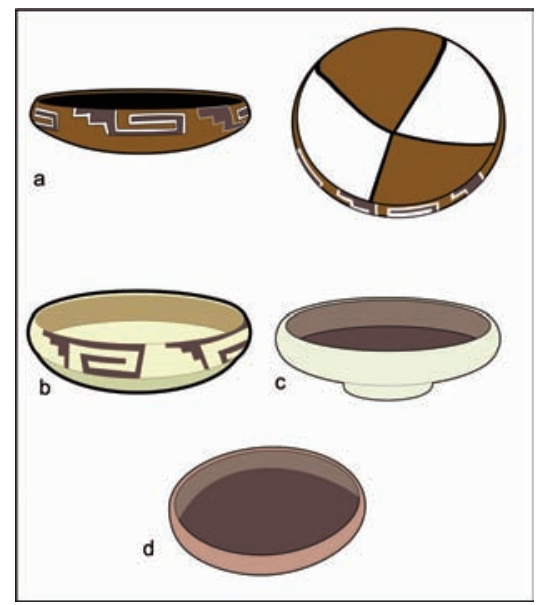

Figura 17. Platos de estilo Cerro del Oro, procedentes de Santa Rosa, valle bajo de Mala. Colección Colegio Santa Rosa de Mala.

Figure 17. Plates from Santa Rosa, Mala valley. Collection School Santa Rosa de Mala.

Los patrones funerarios correspondientes a fardos han sido interpretados como una influencia sureña llegada durante este periodo. Sin embargo, el patrón funerario de fardos y posición en cuclillas es característico en el valle de Asia, inclusive desde los Desarrollos Regionales o Periodo Intermedio Temprano, y como sabemos este patrón viene desde Paracas en el sur. Esto significaría que los valles de Mala, Asia y Cańete poseen una tradición funeraria distinta a la que se produce en la costa central, donde los patrones lima y nievería se relacionan a contextos funerarios extendidos. Los datos de Cerro Salazar y 
Santa Rosa en el valle bajo de Mala, así como de Huaca Malena indican estas características tanto para el Periodo Intermedio Temprano como para el Horizonte Medio. Esta tradición es pues fuertemente sureña y se mantiene durante el Horizonte Medio.

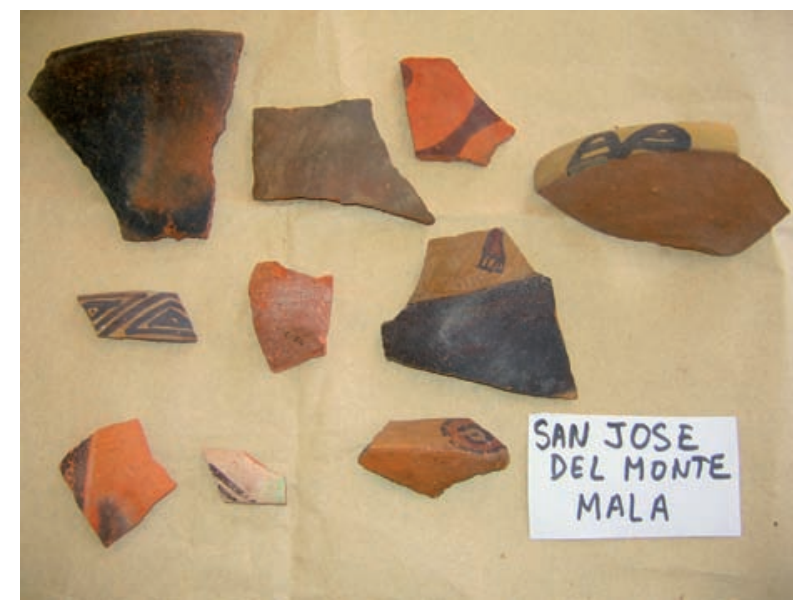

Figura 18. Cerámica de estilo Cerro del Oro, procedente de San José del Monte, valle de Mala. Colección Museo Municipal Huaca Malena.

Figure 18. Ceramics from San Jose of Monte, Mala valley. Collection Municipal Museum Huaca Malena.

En el valle de Asia, ocurren rasgos significativos a destacar. El sitio más importante del Periodo Intermedio Temprano, Huaca Malena, es abandonado, no encontrándose arquitectura de este periodo, y la densidad de cerámica de estilo Cerro del Oro es prácticamente ausente. El sitio no es utilizado ni siquiera como cementerio, lo cual indica un cambio ideológico importante entre las poblaciones de esta época.

Comienzan a aparecer una serie de nuevas aldeas distribuyéndose entre el litoral y el valle medio. Aparecen a veces situándose en la boca de pequeñas quebradas laterales, sin embargo, en realidad se trata de grandes concentraciones que conforman terrazas habitacionales con arquitectura de piedra y adobes cúbicos. El hallazgo de cerámica en proceso de confección en el valle de Asia indica que esta fue fabricada localmente.

Similar fenómeno ocurre en el valle de Mala. La existencia de algunos sitios en la zona de Bujama, implica que durante este periodo se inició la ampliación de la frontera agrícola, pues la zona es alimentada hasta la actualidad por un canal que sale del río Mala. El hallazgo fortuito de un contexto compuesto por una gran cantidad de sartas de hilos de algodón de 
la cual penden cuentas y agujas distribuidas en pares y tríos, implica conjuntamente con el modelo de quipu de algodón reportado por Ruales en Cerro del Oro, que existe una experimentación de formas de contabilidad aún no definidas con claridad que establecen un tipo de ordenamiento contable que es necesario definir.

El fenómeno Cerro del Oro constituye una evidencia de unidad estilística y arquitectónica, reflejo de compartir una ideología y un sistema social, político, religioso y económico. Si la cerámica, los textiles o los contextos funerarios reflejan una identidad propia y diferencias sustantivas entre ellos a manera interna, estas podrían estar relacionadas a aspectos cronológicos aún no resueltos o rasgos internos de esta sociedad. Es evidente que Cerro del Oro representa una unidad en donde el valle de Cañete jugó un rol principal. Desconocemos las relaciones internas entre asentamientos y entre valles vecinos, pero lo que es evidente es que culturalmente son diferentes a los valles de Lurín y Rímac, donde no se ha reportado cerámica de este estilo. ¿Cuál fue el impacto de Wari en las primeras etapas de su desarrollo? ¿Qué significan los estilos regionales que se forman y desaparecen de manera intempestiva? Un aspecto de interés se refiere a la riqueza agrícola de los valles donde existe una mayor densidad de sitios, tal es el caso de Cańete para la costa surcentral y lo mismo ocurre en el valle del Rímac con la presencia del estilo Nievería. En ambos casos, estos estilos innovadores conviven con formas locales propias del periodo anterior, siendo probable que su uso solo haya sido destinado a fines rituales o específicos aún no definidos.

En el valle de Asia aparece asociado al estilo Cerro del Oro una cerámica llana de color marrón y acabado alisado tosco. Esta sin embargo perdura en el tiempo y llega a las épocas 2B y 3 del Horizonte Medio, y recuerda a vasijas del estilo Cuculí definido por Engel para el valle alto de Chilca.

Adicionalmente a la cerámica que caracteriza este estilo, los textiles muestran iconografía relacionada al estilo cerámico y la confección extensiva de tejidos de algodón ha sugerido una marcada independencia de la sierra (Figura 19). Es probable que la alta producción agrícola tanto de Cañete como de los valles indicados establecieron una entidad propia sumamente independiente con respecto a sus materias primas, pero que son receptivas a los estilos propios de este periodo, con especial énfasis a los de Ayacucho y Nasca. La presencia de tejidos en técnica cara de urdimbres discontinuas de pelo de camélido con decoración en tye dye indica una fuerte vinculación con la costa sur y probablemente con la sierra (Figura 20), tomando en consideración que esta técnica y decoración son sumamente difundidas 
desde Nasca para el sur. En relación a los textiles, de acuerdo a información de Mario Ruales, sus estudios en Cerro del Oro reportan una importante cantidad de tejidos de algodón con iconos relacionados a la cerámica.

Para el valle de Chilca, la información de este estilo es escasa, por no decir nula, y la única evidencia corresponde a algunos fragmentos de cerámica de estilo Cerro del Oro en el sitio de Sawilka identificado por Frederic Engel como correspondiente al Imperio Wari. Cabe precisar que Sawilka se ubica estratégicamente en la confluencia de dos quebradas principales de acceso a la sierra.

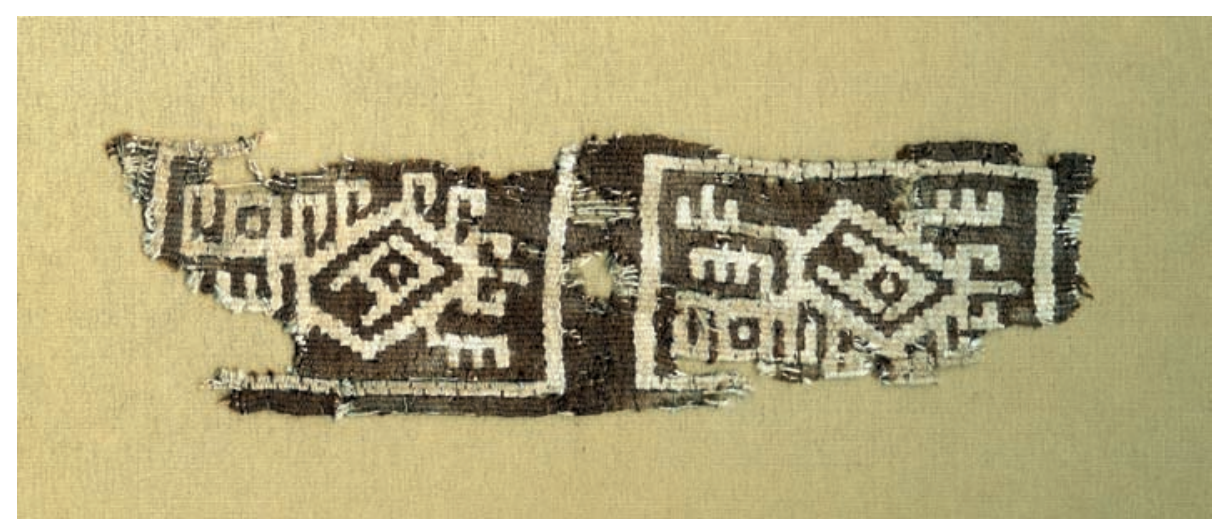

Figura 19. Fragmento de tejido de algodón confeccionado en técnica tapiz ranurado. Estilo Cerro del Oro. Colección Museo Municipal Huaca Malena.

Figure 19. Weave fragment of cotton made in tapestry, Cerro del Oro style textile. Collection Municipal Museum Huaca Malena.

El estilo Cerro del Oro corresponde a una cerámica distribuida entre los valles de Mala, Asia y Cañete, durante la Época 1 del Horizonte Medio.

El sitio de mayor relevancia asociado a esta cerámica es Cerro del Oro en el valle bajo de Cañete, el cual presenta arquitectura monumental con presencia de adobes cúbicos hechos a mano, a lo largo del valle de Cañete, así como asentamientos de carácter habitacional distribuidos entre el valle bajo y medio, tal como se aprecia en el catastro de Williams y Merino. 


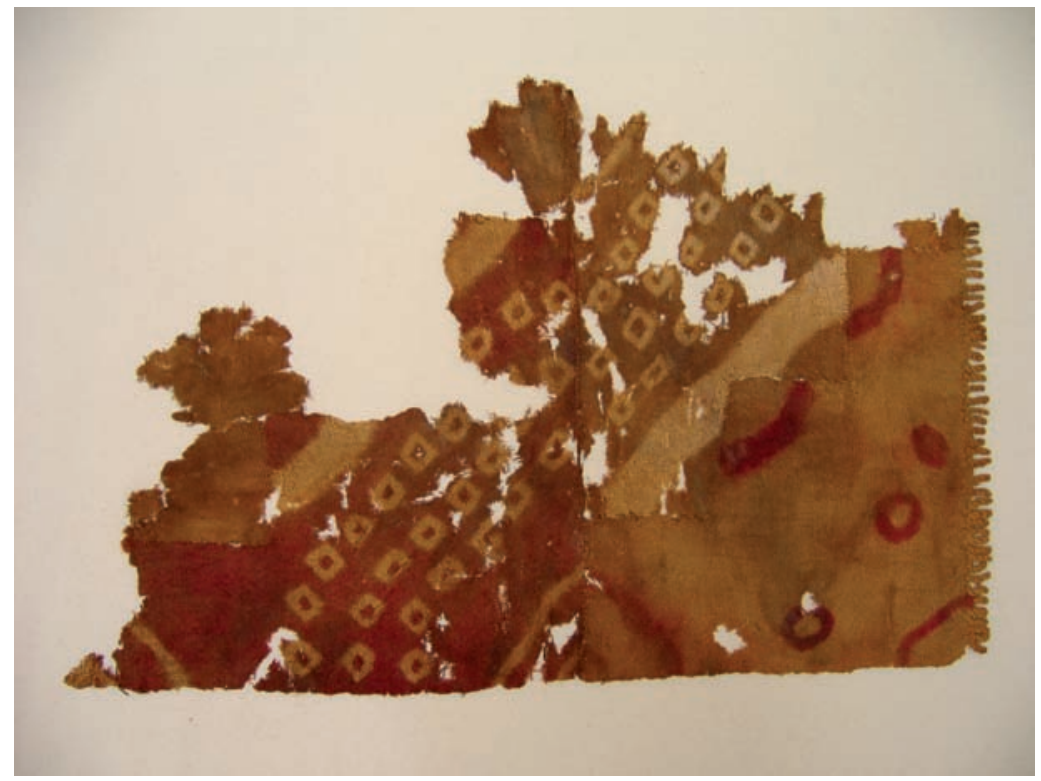

Figura 20. Fragmento de tejido de lana en técnica cara de urdimbres discontinuas con decoración en tie dye y pintado, Horizonte Medio, asociado a cerámica Cerro del Oro. Procede de Socsa, valle medio de Asia. Colección Museo Municipal Huaca Malena.

Figure 20. Weave fragment of wool in expensive technique of warp of discontinuous warps with decoration in tie dye and painted, Middle Horizon, associated to ceramic Cerro del

Oro; Socsa site in the Asia valley. Collection Municipal Museum Huaca Malena.

En el valle de Asia, los asentamientos con cerámica Cerro del Oro se ubican desde el litoral (Las Palmas) hasta el valle medio (Omas). Los sitios ubicados en Omas incluyen también estilos cerámicos locales (Figura 21).

Los sitios son pequeńos pero concentrados en las laderas suaves de cerros de poca pendiente y generalmente utilizan terrazas rellenadas y delimitadas por un muro de piedra de cerro en cuya parte superior se ubican adobes cúbicos (Figuras 22, 23). Los sitios de los valles de Asia y Mala son de menor envergadura comparándolos con los del valle de Cañete, pero los tipos de cerámica son muy similares. 


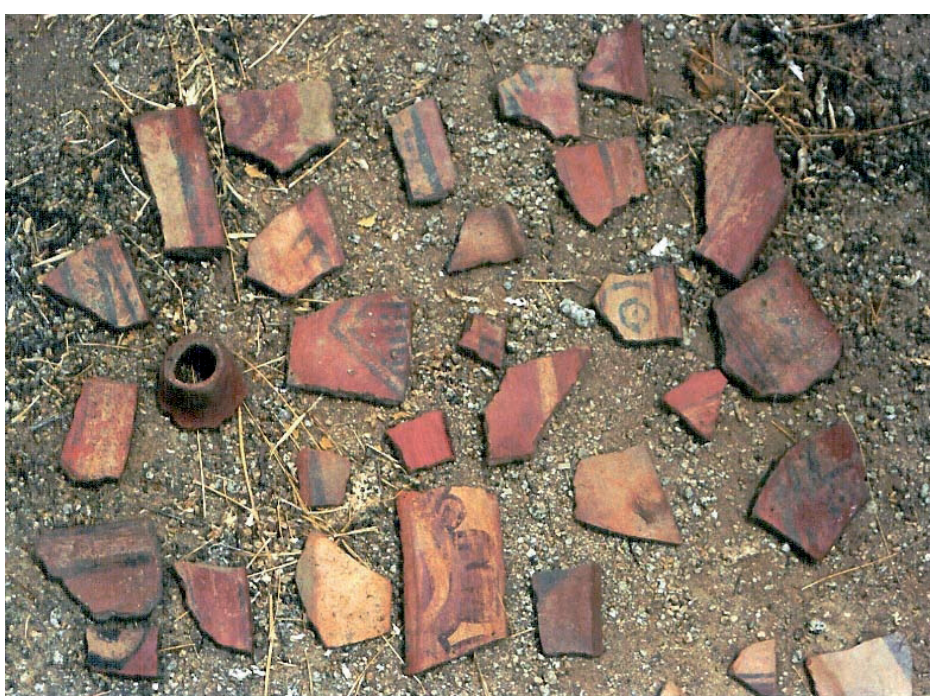

Figura 21. Cerámica del Horizonte Medio procedente de Pueblo Viejo, Omas, incluye fragmento estilo Cerro del Oro. Colección Oliver Huamán.

Figure 21. Ceramic from Pueblo Viejo in Omas, Asia, including frgament in Cerro del Oro style. Collection Oliver Huamán.

Durante la Época 1 del Horizonte Medio, el número de asentamientos se incrementa. Aunque en los valles de Mala y Asia no se distinguen con claridad sitios de gran envergadura, lo que hizo pensar a algunos investigadores que se trataba de largos periodos de abandono de los valles, es evidente que existe un incremento de poblaciones así como un desarrollo arquitectónico importante.

La presencia de íconos relacionados al estilo Chaquipampa, pero de confección local, indica la llegada de importantes influencias de Ayacucho y el incremento de relaciones con la costa.

El estilo Cerro del Oro, en consecuencia, no solo representa una cerámica correspondiente a un solo sitio arqueológico sino que constituye el símbolo de una región durante una época. 


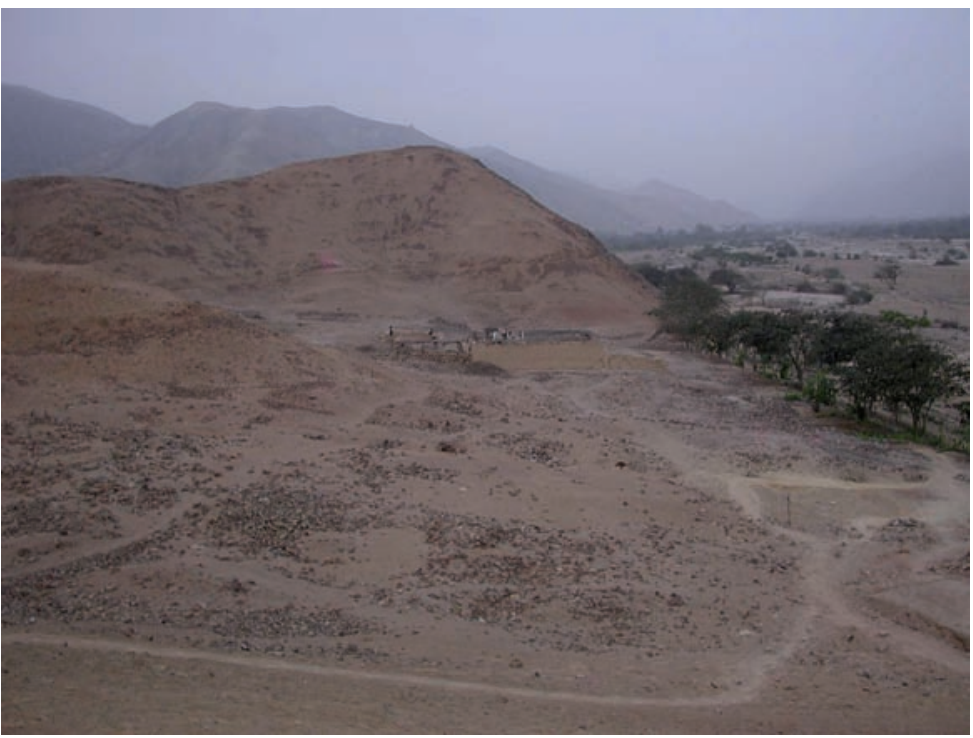

Figura 22. Sitio Cerro Grande o Topas 2, sector Coayllo, valle de Asia. Sitio habitacional con cerámica Cerro del Oro.

Figure 22. Cerro Grande or Topas 2, Coayllo sector in Asia Valley. Habitacional site with ceramic Cerro del oro.

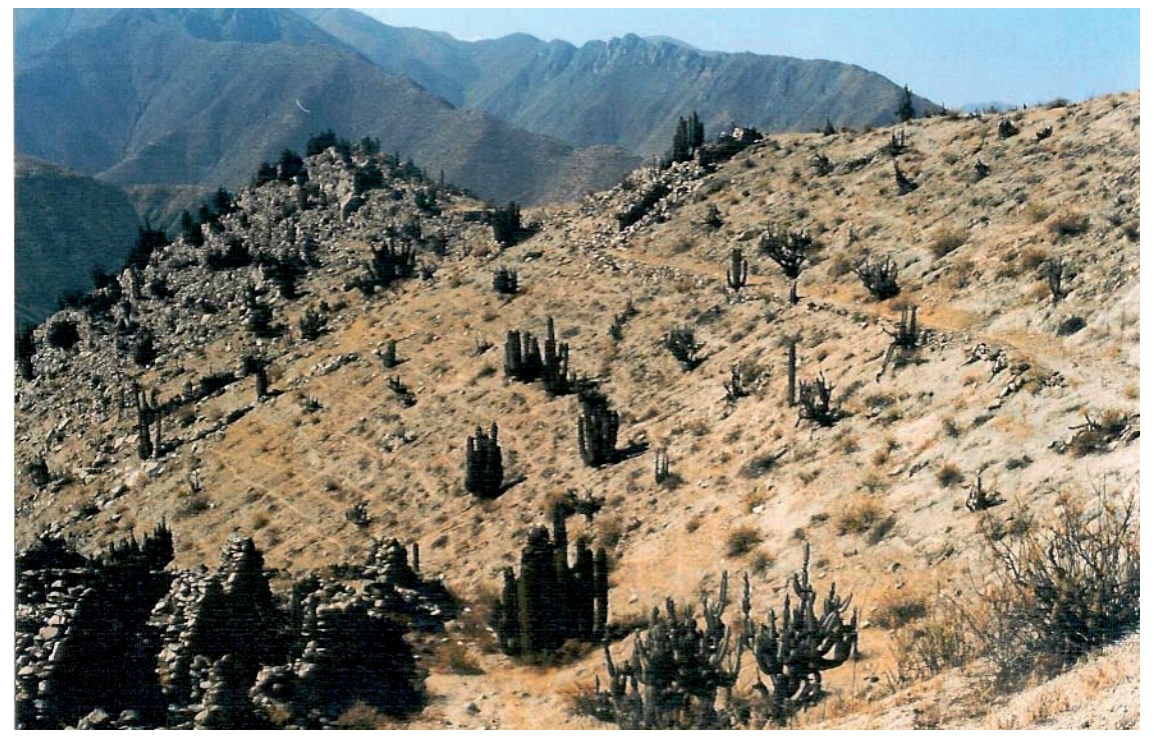

Figura 23. Terrazas habitacionales en Pueblo Viejo de Omas. Se presenta un estilo local y algunos fragmentos de cerámica de estilo Cerro del Oro.

Figure 23. Settlement in terraces: Pueblo Viejo de Omas. One appears a local style and some fragments of style ceramics Hill of Gold. 
Finalmente, los restos óseos asociados a este estilo corresponden a individuos con deformación craneal bilobada. Los fardos funerarios de las épocas 2B y 3 del Horizonte Medio de Huaca Malena están integrados por individuos que no presentan deformación craneana, y están asociados a cerámica llana y tejidos principalmente de pelo de camélido y algodón. Por lo expuesto, las épocas 2B y 3 del Horizonte Medio implican un cambio radical. No se han reconocido sitios habitacionales con claridad, sin embargo, destacan los contextos funerarios emplazados sobre las estructuras de las edificaciones del Periodo Intermedio Temprano de Huaca Malena (Ángeles y Pozzi-Escot 2000, 2001), donde se han reportado contextos funerarios de elite conteniendo fardos de falsa cabeza con finos tejidos wari de similares características a las halladas en Pachacamac por Max Uhle (1903) y en Ancón por Reiss y Stübel (1880-1887). La cerámica asociada a estos contextos es llana y ausente de decoración, a excepción de pocos ejemplares que incluyen cántaros cara-gollete y vasos con la representación del grifo de Pachacamac. Los tejidos de Huaca Malena son particulares, se distinguen tapices del más puro estilo Wari así como otros correspondientes a estilos de la costa central, la costa norte y la costa norcentral subdivididos a partir de la iconografía plasmada principalmente en los tapices.

\section{Tejidos procedentes del valle de Asia}

Un fragmento de tejido tie dye confeccionado con pelo de camélido fue recuperado de la superficie del sitio de Socsa ubicado en las inmediaciones de Coayllo. Se trata de un excepcional fragmento de uncu o camiseta confeccionado en técnica cara de urdimbre de urdimbres discontinuas y teñido mediante tye dye. Presenta flecos estructurales (Figura 20).

Cabe resaltar que en este periodo se sucede un cambio en los patrones de asentamiento, y el número de sitios habitacionales y cementerios crece en gran proporción con relación al periodo anterior. Así existen sitios en el valle bajo y medio donde destaca La Palma, el complejo arqueológico Quisque, Socsa, San Lucas, Las Papas, Pan de Azúcar, Piedra Estrella, Uquira 3, 4, 5 y Tierra Amarilla (Figuras 10, 16, 17, 18, 19). Algunos fragmentos de cerámica de este estilo aparecen en Pueblo Viejo, Omas.

La arquitectura es de piedra y adobes cúbicos, también reportados por Tello (2000) en el sitio Cerro Los Perros, al que denominamos Quisque 1. 


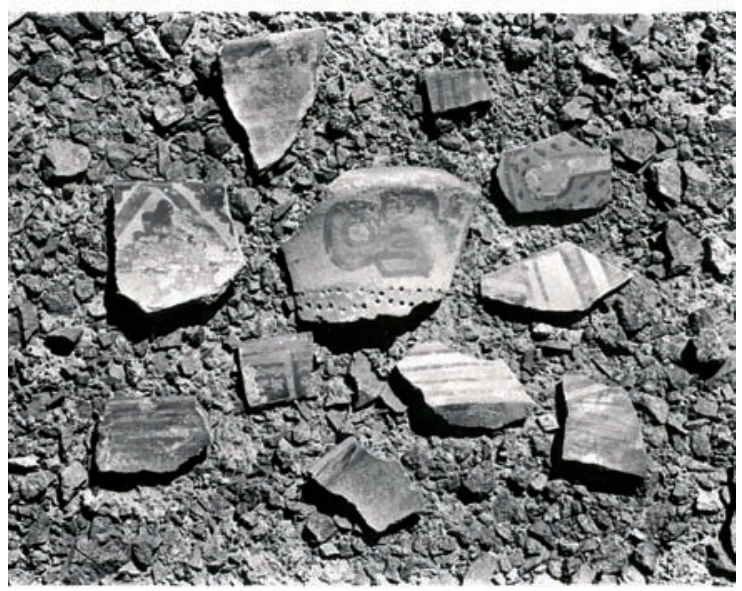

Figura 24 Cerámica de estilo Cerro del Oro, procedente de Tierra Amarilla, valle medio de Asia.

Figure 24. Ceramics of Cerro del Oro style from Tierra Amarilla, Asia valley.

Algunos sitios que tenían material de estilo Cerro del Oro en el valle de Mala fueron reportados durante los trabajos de prospección por encargo del Instituto Nacional de Cultura (Williams y Merino 1976). Ciertamente, los sitios del Horizonte Medio se distribuyen desde el litoral hasta el valle alto. El sitio de La Ensenada (26j 5J01 en la nomenclatura de Williams y Merino) es uno de los sitios con arquitectura y cerámica de estilo Cerro del Oro en el litoral, y la ocupación en la zona parece que fue restringida. Igualmente, en Esquivilca (distrito de San Antonio) y San José del Monte, ubicado en la margen izquierda del valle de Mala a 8 kilómetros del litoral, ambos sitios de carácter aldeano, destaca la presencia de cerámica de estilo Cerro del Oro. En Cerro Salazar, Carmen Gabe, indica la presencia de cerámica de este estilo que aparece asociada a arquitectura de adobes cúbicos hechos a mano. Al parecer en Cerro Salazar existió una aldea de pescadores durante este período. Finalmente, de Mala, en el sector Santa Rosa, procede una importante colección de vasijas de este periodo. Se trataba de fardos en contextos funerarios. El sitio denominado San José del Monte incluye zonas habitacionales con cerámica de estilo Cerro del Oro (Figura 18).

Cańete constituye el valle con mayor cantidad de sitios de este periodo. El sitio de Cerro del Oro, en el actual distrito de San Luis, se encuentra ubicado a la altura del Kilómetro 136 de la carretera Panamericana Sur, y ocupa un área de 120 hectáreas (Ruales 2001: 359) frente a los sitios de menor envergadura existentes en el valle y en los valles vecinos antes mencionados. Desde esa perspectiva, se podría indicar que el sitio de Cerro del Oro debe de 
constituirse en el principal sitio de la costa surcentral durante el Horizonte Medio. Los sitios detectados tanto en Chilca, Mala, Asia y Cañete estarían supeditados bajo algún sistema aún no definido al centro de Cerro del Oro. A este se suman sitios en La Quebrada, Pampa Clarita (cementerio reportado por Héctor Walde), una serie de asentamientos en ambas márgenes del valle y el importante sitio de Rumi Maki (en Lunahuana, reportado por Juan Mogrovejo), una estructura de adobes que encierra una enorme «huanca» de planta rectangular. Los muros de adobes cúbicos presentan pintura mural sobre fondo blanco y crema y diseños delineados en negro y rojo.

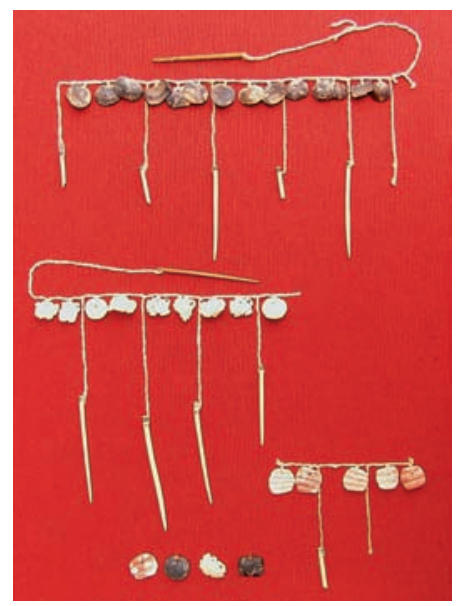

Figura 25. Conjunto de sartas de cuentas y agujas de hueso y madera procedentes de Azpitia, valle de Mala. Colección Museo Municipal Huaca Malena.

Figure 25. Set of strings of accounts and needles of bone and wood coming from Azpitia, Mala valley. Collection Municipal Museum Huaca Malena.

El patrón funerario de cámaras rectangulares o en forma de bota, en donde se depositan los cadáveres enfardelados y en posición flexionada, muestran un patrón sureño, diferente al de la costa central.

Este estilo cerámico a la fecha ha sido reportado entre los valles de Chilca, Mala, Asia y Cañete. Por lo expuesto podemos plantear que durante la época 1 del Horizonte Medio, los mencionados valles conformaron una unidad cultural propia, la misma que surgió asociada a un incremento poblacional, la formulación de una arquitectura propia y cuya cerámica recepciona elementos ideológicos iconográficamente relacionados a Wari a través del uso de elementos de los estilos Chaquipampa, Nasca y Lima, a los que ubica en formas cerámicas locales, algunas de ellas con reminiscencias serranas de Cajamarca, de Wari y de la costa central. Estas nuevas formas 
relacionadas a este estilo son innovadoras toda vez que se alejan de las tradiciones culturales previas (Ángeles y Pozzi-Escot 2000; Gabe 2000). Pero estos sucesos no son aislados a la región. En la costa central paralelamente se suceden una serie de hechos que permiten el desarrollo del estilo cerámico denominado Nievería, que se asocia a la tradición local denominada Lima Tardío. Este estilo Nievería, sin embargo, tiene una distribución limitada. Aparece principalmente en los grandes centros administrativos religiosos del valle de Rímac tales como Maranga, Catalina Huanca y en menor grado en Pucllana. Algunas botellas y platos han sido reportados en la zona de Chaclla, sierra de Lima, y en menor grado se encuentra (con formas limitadas) en los valles del Chillón, Lurín y Chancay. Vasijas nievería proceden igualmente del valle de Fortaleza-Pativilca, algunas del valle de Casma y aparecen como ofrendas foráneas en contextos funerarios de elite en San José de Moro, en el valle de Jequetepeque (Castillo 2001).

Si bien la costa central se caracteriza por la presencia de grandes edificaciones indicativas de un poder centralizado y un sistema político sustentado en una elite gubernamental, los mismos que se concentran en el valle del Rímac; los valles de Chillón y Lurín presentan una menor cantidad de estas edificaciones y las mismas se caracterizan por estar ubicadas en lugares estratégicos.

El estilo Cerro del Oro se distribuye entre los valles de Mala, Asia y Cañete durante las épocas 1 y 2 del Horizonte Medio. Esta cerámica se asocia a arquitectura monumental de adobes cúbicos hechos a mano cuyo centro principal es Cerro del Oro en Cańete. En Asia y en Mala se trata de sitios habitacionales distribuidos entre el valle bajo y medio.

En el valle de Asia, cerámica del estilo Cerro del Oro se ubica en asentamientos pequeños que se encuentran frente al litoral, en las laderas de cerros y bocas de quebradas. Representa un incremento de sitios frente al periodo anterior. La arquitectura es de piedra con adobes cúbicos y en algunos sitios se observan evidencias de actividades artesanales.

Este tipo de evidencia, sugiere que se desarrolló una entidad cultural propia de índole regional, resultado de la presencia de influencias wari, pero con un tipo de carácter propio y local. Es probable que el interés de Wari esté referido a la riqueza agrícola de los valles de Mala y Cańete, mientras que Asia se vio favorecido por el desarrollo de esta entidad.

Agradecimientos: Al Museo Nacional de Arqueología, Antropología e Historia del Perú por permitirnos fotografiar la cerámica de la Colección Tello procedente de Cerro del Oro. A todos los estudiantes de arqueología 
de la Universidad Nacional Mayor de San Marcos que nos acompañaron en los recorridos por el valle de Asia. A Denise Pozzi Escot, Arturo Santos, Ulises Ibánez, Mirtha Cruzado y Héctor Walde y en especial a los organizadores del simposio La producción y distribución de cerámica como indicador social y politico en los Andes prehispánicos y coloniales y a los editores de la Revista Chilena de Antropología por su especial deferencia.

\section{BiBLIOGRAFÍA}

Ángeles, R. 2002. "Un hallazgo del periodo formativo en el valle de Asia". Arqueología y Sociedad 14: 99-122.

Ángeles, R. 2003. Arqueología del valle de Asia. Cuadernos del Patrimonio Cultural 1. Museo Municipal Huaca Malena. Lima.

Ángeles, R. y D. Pozzi Escot. 2000. "Investigaciones arqueológicas en Huaca Malena, valle de Asia”. Arqueológicas 24: 63-77.

Ángeles, R. y D. Pozzi Escot. 2001. "Textiles del Horizonte Medio. Las evidencias de Huaca Malena, valle de Asia". Boletín de Arqueología PUCP 4: 401-424.

Ángeles, R. y D. Pozzi Escot. 2004. "Del Horizonte Medio al Horizonte Tardío en la Costa Sur Central: el caso del valle de Asia". Bulletin de l'Institut Français d'Études Andines 33 (3): 861-886.

Ángeles, R. y D. Pozzi Escot. 2005. "Un fardo funerario de Huaca Malena, valle de Asia”. Corriente Arqueológica 1: 119-148.

Baca, E. 2001. "Establecimiento estatal inka en el valle de Asia, Uquira". Actas del XII Congreso Peruano del Hombre y la Cultura Andina, vol. II: 174-194. Lima.

Castillo, L. J. 2001. "La presencia de Wari en San José de Moro". Boletín de Arqueología PUCP 4: 143-179.

Coello, A. 1991. "Uquira: un sitio inka”. El Peruano, 1 y 7 de abril: 1-3. Lima.

Engel, F. 1963. "A preceramic settlement on the Central Coast of Peru: Asia, Unit 1". Transactions of the American Philosophical Society 53 (3): 1-139.

Engel, F. 1987. De las Begonias al Maiz. Vida y producción en el Perú antiguo. Centro de Investigaciones de Zonas Áridas (CIZA). Universidad Nacional Agraria, La Molina. Lima. 
Gabe, C. 2000. Investigaciones arqueológicas en Cerro Salazar, Mala. Serie de Investigaciones CEAMA, 1. Lima.

Kroeber, A.L. 1937. "Archaeological Explorations in Peru. Part IV. Cañete Valley. First Marshall Field Archaeological Expeditions to Peru". Anthropology Memoirs 2 (4): 221-273.

Menzel, D. 1968. La cultura Huari. Compañía de Seguros y Reaseguros Peruano-Suiza. Lima.

Menzel, D. 1971. "Estudios arqueológicos en los valles de Ica, Pisco, Chincha y Cañete". Arqueología y Sociedad 6: 1-167.

Negro, S. 1982. "Ukira, arquitectura Inca de la costa central". Revista de la Universidad Ricardo Palma 5: 83-98.

Reiss, J. W. y M. A. Stübel. 1880-1887 The Necropolis of Ancon in Peru: a contribution to our knowledge of the culture and industries of the Empire of the Incas, Being the results of excavations made of the spot (traducción de A. J. Keane). 3 volúmenes. A. Asher \& Co, Berlín.

Ruales, M. 2001. "Investigaciones en Cerro del Oro, valle de Cañete". Boletín de Arqueología PUCP 4: 359-399.

Stumer, L. 1971. "Informe preliminar sobre el recorrido del valle de Cańete". Arqueologia y Sociedad 5. 23-35.

Tello, J. C. 2000. Arqueología del valle de Asia: Huaca Malena. Cuadernos de Investigación del Archivo Tello 2. Museo de Arqueología y Antropología de la Universidad Nacional Mayor de San Marcos. Lima.

Uhle, M. 1903. Pachacamac. Report of the William Pepper, M. D., LL. D., Peruvian Expedition of 1896. Department of Archaeology, University of Pennsylvania. Philadelphia.

Williams, C. y M. Merino. 1974. Inventario, Catastro y Delimitación del Patrimonio Arqueológico del Valle de Cañete. Centro de Investigación y Restauración de Bienes Monumentales. Instituto Nacional de Cultura. Lima.

Williams, C. y M. Merino. 1976. Inventario, Catastro y Delimitación del Patrimonio Arqueológico del Valle de Mala. Centro de Investigación y Restauración de Bienes Monumentales. Instituto Nacional de Cultura. Lima. 